\title{
RETOMANDO O ESTRUTURALISMO ${ }^{1}$
}

\author{
José Maria Alves da Silva
}

Resumo: A crise econômica mundial resgatou o keynesianismo. As atuais tendências da economia brasileira, no que tem sido chamado de "reprimarização", tornam oportuno recolocar o estruturalismo em posição de maior destaque no debate econômico nacional. Esse é o objetivo principal deste artigo. Para isso, discute-se uma versão do modelo macroeconômico de "dois-setores", mediante o qual se procurou mostrar sua pertinência como guia de pensamento para uma série de questões socioeconômicas relevantes, especialmente para os países do terceiro mundo. Procurou-se mostrar também sua consistência com certas evidências empíricas e como pode ser usado para fundamentar críticas objetivas a certas estratégias econômicas que têm sido propostas para o Brasil.

Palavras-chave: Estruturalismo, macroeconomia, modelo de dois setores, Brasil.

\section{Introdução}

A experiência neoliberal da política brasileira deve pelo menos ter servido para mostrar que os entraves ao desenvolvimento econômico nacional não serão superados sem grandes transformações de ordem estrutural e institucional. Paradoxalmente, entretanto, os referenciais analíticos mais indicados para nortear políticas de enfrentamento dos problemas que se apresentam permanecem ainda em relativo ostracismo.

Afirma-se, frequentemente, que as chances de sucesso do país na economia globalizada serão muito reduzidas, no médio e longo prazo, se nada for feito para reduzir o custo-Brasil. Entre os principais determinantes desse óbice à competitividade nacional, estão carências infraestruturais, deficiências de ordem logística e anacronismos institucionais agravados por mais de duas décadas de contenção do investimento público³ ${ }^{3}$.

\footnotetext{
Recebido em: 25/11/09; Aceito em: 18/03/10.

2 Professor do Departamento de Economia Rural da Universidade Federal de Viçosa. E-mail: jmasilva@ufv.br.

3 Tomando como exemplo a área de transportes, é indiscutível o enorme atraso brasileiro em relação aos países adiantados. Enquanto no primeiro mundo a pesquisa tecnológica está em vias de permitir a implantação de trens-bala supervelozes (com velocidades em torno de $500 \mathrm{~km} / \mathrm{h}$ ), no Brasil, a rede ferroviária foi sucateada nas duas últimas décadas. Nos outros modais, verificam-se problemas de caos aéreo, subinvestimentos na malha rodoviária e dependência estrangeira em navegação marítima.
} 
Aos fatores estruturais juntam-se outros de ordem institucional, responsáveis pela parafernália fiscal, disfunções no sistema de crédito, letargia da justiça, corrupção da administração pública e atrofia dos aparelhos de segurança, entre outras importantes mazelas nacionais e também causas importantes do chamado custo-Brasil ${ }^{4}$.

A reversão do balanço de transações correntes, iniciada ao final do segundo mandato do governo Fernando Henrique Cardoso, tem sido muito decantada. É inegável que, para isso, contou, principalmente, um notável crescimento das exportações. Por trás desse crescimento, estão os êxitos produtivos do setor agropecuário e outros ligados à pauta típica de exportações de países periféricos, mas é preciso levar em conta que muito desse desempenho se deve a condições favoráveis que vieram de fora para dentro e sobre as quais não se tem controle nem garantias de continuidade.

A pauta de exportações brasileiras continua sendo excessivamente concentrada em bens de baixa relação valor/volume, como grãos (soja, café, milho), produtos florestais, minério de ferro e produtos siderúrgicos, cujas produções se realizam a elevados custos ambientais, que não são contabilizados em nenhum lugar, e cujo escoamento em maior escala requer ampliações de infraestrutura logística e espaços adicionais em navios de alta tonelagem. Na falta disso, a dependência do país para com as tradings de capital estrangeiro só tende a aumentar. Tais atividades exportadoras podem até gerar as divisas necessárias ao cumprimento do serviço do passivo externo, mas são ineficazes para a geração de renda e promoção do desenvolvimento nacional.

É curioso notar que essa tendência de retorno à condição primárioexportadora da economia brasileira, que os estruturalistas tanto

\footnotetext{
Por causa da falta de capacidade e da falta de agilidade dos portos, o país tem perdido bilhões de dólares anuais só de multas por descumprimento de contratos, somados a outros tantos de evasão de divisas no contrabando facilitado pelo esvaziamento da guarda costeira e da polícia rodoviária. A falta de segurança nas vias de transporte acarreta enormes despesas para as companhias transportadoras com seguros e manutenção de frota, o que encarece os fretes. O excesso de burocracia inibe o empreendedorismo e dificulta o acesso às linhas especiais de crédito dos bancos estatais. A multiplicidade tributária, além de onerar o setor produtivo, constitui fonte de vários tipos de perturbações e incômodos que atingem, principalmente, a pequena e a média empresa.
} 
condenavam, esteja passando ao largo do debate acadêmico ${ }^{5}$. O que existe hoje de polêmica, no meio dos economistas profissionais, está no que tem sido chamado de controvérsia entre monetaristas e desenvolvimentistas. O atual "monetarismo versus desenvolvimentismo", entretanto, tem pouco a ver com o "monetarismo versus estruturalismo" do passado, a começar pelo fato de que os monetaristas de antigamente pareciam mais estruturalistas que os desenvolvimentistas de hoje. Eugênio Gudin, por exemplo, considerado o mais acirrado dos monetaristas brasileiros, mantinha um debate cordial com o estruturalista argentino Raul Prebisch, sem que se possa dizer que tenha omitido ou negligenciado questões de ordem estrutural, como bem indicam as seguintes passagens do seu clássico manual de economia monetária:

“... devemos chamar atenção para o fato de que,
em países de produção primária, as medidas de
caráter estrutural têm especial importância [...]
Um país cuja economia repousa sobre um número
muito limitado de produtos torna-se especialmente
vulnerável à depressão, em comparação com as
que apresentam diversidade de produtos agrícolas
e industriais [...] Outra medida de reforço
estrutural dos países de produção primária é a
de uma gradativa industrialização, para
diversificar a economia e escapar em parte aos
percalços cíclicos...” (GUDIN, 1976, p. 239-240).

Não obstante, é um exagero de linguagem chamar de desenvolvimentismo um movimento que meramente clama por maior crescimento econômico. Desenvolvimentismo é o nome que se deveria dar a um movimento contra o subdesenvolvimento, algo que há muito tempo deixou de existir no Brasil ${ }^{6}$.

Se é que se pode falar que atualmente existe debate acadêmico em questões de economia brasileira. Na verdade, o debate de temas polêmicos, como o custo-Brasil, parece mais visível nos meios empresarial e político do que no acadêmico.

6 Apesar dos êxitos do agronegócio e de ainda estar no elenco dos vinte maiores países por tamanho de PIB, o Brasil é um país de enormes desigualdades pessoais e regionais, com um conjunto dominado pelo atraso, pela pobreza e pela ignorância. É bem sabido que, em termos de indicadores sociais, que são os que devem prevalecer na definição da linha que separa os países desenvolvidos dos subdesenvolvidos, o Brasil está numa situação de clara inferioridade. 
O estruturalismo, como teoria ou doutrina, foi, de fato, um movimento desenvolvimentista que é preciso resgatar, a bem do enriquecimento do debate econômico brasileiro.

\section{Características da abordagem estruturalista}

O termo 'estruturalismo' tem sido empregado, com diferentes significados, em diferentes contextos científicos e culturais. Na ciência econômica, designa-se por ele uma das correntes críticas do pensamento dominante ou ortodoxo. Na perspectiva estruturalista, para credenciar-se como ciência positiva das leis de mercado, a partir da explicação lógico-dedutiva de comportamentos individuais de agentes e unidades econômicas, a teoria ortodoxa tem de abstrair as especificidades das estruturas produtivas, as instituições e os demais fatores de natureza sociológica que integram a realidade concreta dos sistemas econômicos nacionais. Em razão disso, no que diz respeito ao desenvolvimento econômico de longo prazo e à estabilidade sistêmica, ela acaba tendo muito pouco a recomendar aos governos de países subdesenvolvidos, além de obediência aos princípios do liberalismo e às regras de austeridade em matéria de gestão fiscal e monetária. Essas recomendações são convenientes para os países ricos, que, no passado, souberam criar estruturas e desenvolver instituições que os colocaram no centro dinâmico da economia mundial. Elas incentivam a paralisia dos países retardatários, reforçando sua relação de dependência para com os adiantados ${ }^{7}$.

A abstração das características estruturais e institucionais/sociológicas significa, entre outras coisas: 1) utilizar as mesmas hipóteses para explicar o comportamento de mercado entre setores substancialmente heterogêneos; 2) abstrair as implicações macroeconômicas das disputas entre diferentes classes sociais ou categorias profissionais; e 3) desconsiderar a existência de dualismos e polarizações. Para os estruturalistas, no que concerne a alguns problemas macroeconômicos cruciais, resultam disso não só uma propensão à confusão entre causas

Relação centro-periferia, como se referia o economista argentino Raul Prebisch. 
fundamentais e fatores sancionadores de problemas macroeconômicos, como também suas principais fraquezas como guia de políticas adequadas aos países subdesenvolvidos.

Conforme salientava Kalecki (1977), os problemas econômicos cruciais desses países decorrem da escassez de capital, da presença de gargalos estruturais e de dinâmicas intersetoriais incompatíveis com crescimento equilibrado, problemas que não podem ser resolvidos meramente com políticas de estabilização e manejo de instrumentos fiscais/monetários, diferentemente do que ocorre nos países ricos, nos quais a tarefa central da política econômica consiste em administrar a demanda efetiva para manter as taxas de desemprego e inflação dentro de certos limites desejáveis ou pelo menos aceitáveis. Nos países desenvolvidos, os processos de acumulação de capital e modernização tecnológica já atingiram estágios suficientemente avançados para determinar a existência de potencial produtivo bem maior que a capacidade de absorção social do produto. Portanto, nestes, a preocupação principal é garantir a sustentação da demanda, em níveis adequados. Em síntese, enquanto os problemas cruciais dos países ricos provêm da instabilidade da demanda, nos países pobres eles residem na deficiência da oferta. Algo parecido com isso, ainda que por vias tortas, parece estar sendo agora reconhecido por um dos expoentes do mainstream, conforme indicam as seguintes passagens de um texto recente sobre perspectivas da teoria macroeconômica:

Trying to smooth those fuctuations through the use of policy would be wrong. How relevant this argument is for rich, diversified, economies, remains unclear to me, and I suspect that the argument for keeping output on a smooth path is still a strong one. It is, however, surely relevant to emerging economies, affected by terms of trade shocks if they are commodity exporters, or sudden shifts in capital flows. Trying to achieve a smooth path in the face of such shocks is likely, from a welfare viewpoint, to be counterproductive. (BLANCHARD, 2008, p. 9). 
É significativo também que a obra de Friedrich List, uma referência fundamental do estruturalismo, esteja sendo resgatada por novas escolas de pensamento econômico. Veja-se, por exemplo, o seguinte trecho selecionado de uma conceituada obra em economia da inovação:

\begin{abstract}
Friedrich List criticou os economistas clássicos por atribuírem uma insuficiente atenção à ciência, à tecnologia e às aptidões no crescimento das nações. Seu livro The National System of Political Economy (1841) poderia perfeitamente ter sido denominado "The National System of Inovation". Sua principal preocupação era o problema de a Alemanha ultrapassar a Inglaterra e com relação aos países subdesenvolvidos (caso da Alemanha em relação à Inglaterra, na época), ele defendia não somente a proteção das indústrias nascentes como também a formulação de uma ampla variedade de politicas destinadas a acelerar ou a tornar possível a industrialização $e$ o crescimento econômico [...] Ele claramente antecipou muitas das atuais teorias sobre os "sistemas nacionais de inovações" (LUNDVALL, 1992; NELSON, 1993; MJOSET, 1992). (FREEMAN e SOETE 2008, p. 504).
\end{abstract}

Na literatura econômica especializada, as ideias estruturalistas têm também sido fonte de inspiração da pesquisa com modelos macroeconômicos. $\mathrm{Na}$ verdade, o que tem sido chamado de macroeconomia estruturalista é uma variedade de modelos macroeconômicos desagregados. A classe mais simples desses modelos é constituída pelas versões de dois setores, agriculturaindústria, que, no passado, foram bastante utilizados na análise de inflação e crescimento econômico. Veja-se, por exemplo, Kaldor (1976), Sayad (1979), Ramos (1985), Parkin (1990) e Silva (1993), entre outras referências nacionais e estrangeiras. A outra classe, mais complexa, é constituída pelos modelos multissetoriais, a exemplo de Taylor (1990), (2004) e Haan (1995). 
Para resgatar, objetivamente, algumas das principais proposições e insights estruturalistas, no intuito de contribuir para enriquecer o atual debate sobre os rumos da economia brasileira, é mais conveniente trabalhar com a versão "dois-setores". Apesar de sua estrutura simplificada, esta versão constitui avanço analítico em relação aos modelos macroeconômicos agregativos, na medida em que, além de tratar da determinação da renda, do emprego e do nível geral dos preços, como aqueles, leva em conta também a determinação de preços relativos e, por extensão, a questão da distribuição funcional da renda entre pelo menos três classes sociais.

Trabalhar com modelos requer sempre algum trade-off entre simplicidade e realismo. Mas, como bem afirma Romer (2000), um modelo que se propõe a lançar luzes sobre certas características importantes da realidade não precisa e nem deve ser complicado; ao contrário, quanto mais simples, mais objetivas e fáceis de compreender serão as respostas que se obtêm das perguntas que se faz a ele. Nesse caso, em vez de defeito, a simplificação será uma virtude, desde que não leve a respostas erradas. Poucos modelos econômicos caem tão bem dentro desse espírito quanto o que será discutido a seguir.

\section{Descrição e interpretação do modelo}

A versão, aqui trabalhada, refere-se a uma economia hipotética desagregada em dois setores produtivos perfeitamente integrados verticalmente; o setor agrícola, que doravante será representado pelo subscrito $(a)$, e o industrial, representado pelo subscrito $(i)$. O primeiro produz alimentos e o segundo, bens manufaturados de consumo e de capital. Supõe-se que o mercado dos bens agrícolas seja perfeitamente competitivo e que o de bens industriais afaste-se dessa condição num grau que será doravante denominado "grau de monopolização". 
Como corolário da hipótese de competição perfeita, o mercado agropecuário é flex-price, no sentido de Hicks (1974), de modo que toda e qualquer discrepância ex-ante entre procura e oferta será eliminada ex-post pela livre movimentação do preço ${ }^{8}$. Na hipótese adicional de oferta perfeitamente inelástica, isso implica que a quantidade de equilíbrio será totalmente determinada pelos condicionantes da oferta e o preço totalmente determinado pelos condicionantes da demanda. $\mathrm{O}$ mercado industrial, em contraste, é suposto como fix-price. Admite-se que cada firma opere sempre com certa margem de capacidade ociosa e tenha poder de decisão sobre o preço de seu produto. Preço e grau de utilização de capacidade ociosa são variáveis estratégicas. O primeiro, conforme Kalecki (1971), é definido em função dos custos de produção e dos preços praticados no resto da indústria, dadas as metas de lucratividade, enquanto o segundo depende do planejamento de longo prazo, especialmente no que se refere ao caminho de expansão da firma e suas metas de market share. Desse modo, o produto e o nível de preços agropecuários são determinados, simultaneamente, pelas forças de demanda e oferta, enquanto no setor industrial o preço será determinado pela oferta e o produto, pela demanda.

Admite-se que a renda gerada em ambos os setores seja apropriada por três classes sociais - trabalhadores industriais, capitalistas e agricultores, cujas respectivas demandas de consumo serão denotadas por $C_{w}, C_{l}$ e $C_{a}$, respectivamente ${ }^{9}$.

As demais hipóteses e pressupostos estão subjacentes ao seguinte sistema de equações:

\footnotetext{
No sentido de Hicks (1976), mercados fix-prices são aqueles em que os preços são determinados pelos custos ou estabelecidos contratualmente, enquanto os flex-prices são aqueles em que os preços flutuam livremente ao sabor da oferta e da demanda.

9 Essa pressuposição é bem do tipo que vem para bem de simplificação e objetividade, sem nenhum inconveniente analítico que pudesse levar o modelo a "dar respostas erradas", mesmo porque ela não é necessária. De fato, não é preciso supor uma sociedade abstrata em que inexistem outras categorias profissionais além de operários urbanos e trabalhadores rurais. As atividades terciárias podem ser consideradas, implicitamente, como funções necessárias, cujo exercício requer a apropriação, por outras categorias profissionais, de parte do excedente econômico gerado nas atividades industriais e agropecuárias.
} 


$$
\begin{aligned}
& Q_{a}=\theta\left(\frac{P_{a}}{P_{i}}\right)^{\varepsilon} ; \\
& D_{a}=x+a+\frac{c W}{P_{a}} ; \\
& x=\psi\left(\frac{P_{a}}{P_{i}}\right)^{-\eta} ; \\
& D_{i}=C_{w}+C_{l}+C_{a}+I ; \\
& C_{w}=(1-c) \frac{W}{P_{i}} ; \\
& C_{l}=(1-s-\mu) \frac{L}{P_{i}} ; \\
& C_{a}=(1-f) \frac{P_{a} Q_{a}}{P_{i}} ; \\
& P_{i} Q_{i}=W+L+J ; \\
& L=m(W+J) ; \\
& J=j W ; \\
& W=w N ; \\
& X=x P_{a} ; \\
& M=\mu L+j W ; \\
& D_{a}=Q_{a} ; \\
& D_{i}=Q_{i} ;
\end{aligned}
$$


sujeito às condições necessárias ${ }^{10}$ : $0<c<1 ; 0<s<1,0<m<1,0<$ $f<1, j<1$ e $\mu<1$.

A equação (1) representa o produto agropecuário ofertado $\left(Q_{a}\right)$, como função proporcional do nível de preços agropecuários $\left(P_{a}\right)$ relativo aos preços industriais $\left(P_{i}\right)$; o parâmetro $\theta$ sintetiza os fatores de deslocamento da oferta agropecuária, via aumento de produtividade ou expansão da fronteira agrária; e $\varepsilon$ denota a elasticidade-preço. A equação (2) representa a demanda total do produto agropecuário, como soma de uma componente externa $(x)$, e da demanda alimentar interna, especificada como função linear da massa salarial $(W)$ relativa ao preço dos alimentos $\left(P_{a}\right)$. Essa especificação para a demanda interna pressupõe que a classe trabalhadora, em geral, tenha carências alimentares a serem satisfeitas pelo aumento dos salários, ou agravadas pela diminuição destes, ao passo que as rendas das famílias de classe média e alta estarão muito acima do ponto de saturação nutricional, de modo que sua propensão marginal a consumir alimentos será zero. Assim, no parâmetro $a$, que doravante será denominado de "consumo alimentar autônomo", inclui o consumo próprio dos agricultores e das famílias abastadas, rurais ou urbanas ${ }^{11}$. A equação (3) estabelece a demanda externa do produto agropecuário, como função inversa do preço relativo; o parâmetro $\psi$ capta a ação dos fatores exógenos; e $\eta$ denota a elasticidade-preço.

A equação (4) apresenta a demanda total do produto industrial, como soma das demandas de consumo das três classes $\left(C_{w}, C_{b}, C_{a}\right)$ mais a demanda de investimento $(I)$. Conforme indicado pelas equações (5), (6) e (7), as demandas de consumo de cada classe são admitidas como funções proporcionais das respectivas rendas relativas ao nível de preço industrial. Ao admitir, a lá Kalecki (1977), que os trabalhadores não poupem, a propensão a consumir bens industriais será o complemento $(1-c)$ da propensão a consumir bens agropecuários. Considerando que os coeficientes $s$ e $f$ representem as propensões a poupar dos capitalistas e dos agricultores, respectivamente, e $\mu$ denote a propensão a consumir ${ }^{10}$ Essenciais porque constituem condições necessárias para a existência de equilíbrio estável.

11 Uma função assintótica seria mais apropriada para representar demandas alimentares que convergem para um ponto de saturação, mas isso apenas faria complicar a álgebra, sem acrescentar nada de substantivo às conclusões. 
bens importados dos primeiros, segue-se que as frações complementares $(1-s-\mu)$ e $(1-f)$ representam, respectivamente, as propensões a consumir bens industriais de ambas as classes.

Conforme descrito na equação (8), o valor bruto da produção industrial deve ser exatamente igual ao total da renda apropriada pelos trabalhadores $(W)$ e capitalistas $(L)$ mais a despesa com insumos importados $(J)$. A equação (9) fundamenta-se na hipótese de validade do princípio do custo total, conforme LABINI (1980), em que $m$ denota a margem de lucro sobre o custo direto. A equação (10) estabelece o custo dos insumos importados $(J)$ como uma proporção $(j)$ da renda dos trabalhadores $(W)$, a qual, segundo a equação (11), é determinada pelo produto da taxa de salário $(w)$ pela quantidade de trabalho empregada $(N)$.

A equação (12), simplesmente, define o valor nominal das exportações $(X)$ como produto do quantum demandado $(x)$ pelo preço $(P)$, na hipótese de que o sistema em questão se refere a um país exclusivamente agroexportador. Pela equação (13), pressupõe-se que as importações totais $(M)$ sejam constituídas de bens de consumo superior demandados pelos capitalistas, como proporção $(\mu)$ do lucro $(L)$, e matérias-primas industriais, conforme estabelecido na equação (10). As equações (14) e (15) representam as condições de equilíbrio de ambos os mercados.

Doravante, para que não pairem dúvidas, deve ficar claro que as variáveis relativas às demandas e ofertas $\left(Q_{a}, D_{a}, Q_{i}, C_{w}, C_{l}, C_{a}\right.$ e $\left.I\right)$ estão todas definidas em termos reais.

\section{Operação e análise}

Das equações (8), (9), (10) e (11), deduz-se que

$$
P_{i} Q_{i}=z(1+j) w N
$$

e

$$
L=\frac{m P_{i} Q_{i}}{z},
$$


em que $z=(1+m)$ define o mark-up, designação usual para o fator multiplicativo aplicado ao custo unitário direto para determinar o preço de venda. Sob a suposição que a diferença entre os preços e os custos diretos unitários reflete o grau de afastamento da competição pura, o mark-up atua no modelo como indicador do grau de monopolização da economia.

Dividindo ambos os lados de (16) por $\left(Q_{i}\right)$ e usando (11), a equação (16) converte-se na seguinte equação de preço industrial:

$$
P_{i}=z(1+j) w b^{-1},
$$

em que $b$ denota a produtividade do trabalho, estimada pela razão entre o produto e o nível de emprego no setor industrial, ou seja,

$$
b=\frac{Q_{i}}{N} .
$$

Tendo em vista que a taxa de salário ( $w$ ) é tratada como uma variável exógena, assim como a demanda de investimento $(I)$, o nível de preço industrial $\left(P_{i}\right)$ também é determinado exogenamente, uma vez que, na equação (18), $z$ é um parâmetro do planejamento empresarial, enquanto $b$ e $j$ são coeficientes técnicos.

Substituindo (1), (2) e (3) em (14) e levando em conta (11) e (16), podese chegar à seguinte relação funcional entre as variáveis endógenas $\left(P_{d} /\right.$ $\left.P_{i}\right)$ e $Q_{i}$, que é consistente com o equilíbrio parcial do mercado agropecuário, para cada conjunto dado de valores das variáveis exógenas e parâmetros:

$$
Q_{i}=\alpha\left(\frac{P_{a}}{P_{i}}\right)^{1+\varepsilon}+\gamma\left(\frac{P_{a}}{P_{i}}\right)^{1-\eta}+\beta\left(\frac{P_{a}}{P_{i}}\right)
$$


em que $\alpha=\frac{z \theta(1+j)}{c} ; \gamma=-\frac{z \psi(1+j)}{c}$ e $\beta=-\frac{z a(1+j)}{c}$.

Similarmente, substituindo as equações (5), (6) e (7) em (4), e levando em conta (1), (11), (15), (16) e (17), pode-se chegar à seguinte relação consistente com equilíbrio parcial do mercado industrial:

$Q_{i}=\lambda+\phi\left(\frac{P_{a}}{P_{i}}\right)^{1+\varepsilon}$

em que $\lambda=\frac{z(1+j) I}{c+j+m(1+j)(s+\mu)}$ e $\phi=\frac{\theta z(1+j)(1-f)}{c+j+m(1+j)(s+\mu)}$

Igualando (20) a (21), obtém-se a seguinte expressão de determinação da razão de preços de equilíbrio simultâneo de ambos os mercados:

$$
(\alpha-\phi)\left(\frac{P_{a}}{P_{i}}\right)^{1+\varepsilon}+\gamma\left(\frac{P_{a}}{P_{i}}\right)^{1-\eta}+\beta\left(\frac{P_{a}}{P_{i}}\right)=\lambda .
$$

Não existe uma solução geral definida para equações desse tipo. Contudo, podem-se obter soluções definidas para casos especiais em que as elasticidades $\varepsilon$ e $\eta$ assumem valores 0 ou 1 . Há, portanto, quatro casos possíveis: I) $\varepsilon=1$ e $\eta=1$; II) $\varepsilon=1$ e $\eta=0$; III) $\varepsilon=0$ e $\eta=1$; e IV) $\varepsilon=$ 0 e $\eta=0$. O quadro abaixo apresenta as expressões algébricas das soluções de forma reduzida, para cada um desses quatro casos. 
Quadro 1 - Equações das soluções de forma reduzida

\begin{tabular}{|c|lc|}
\hline CASOS & \multicolumn{2}{|c|}{ SOLUÇÕES } \\
\hline I & $\frac{P_{a}}{P_{i}}=\frac{-\beta \pm \sqrt{\beta^{2}-4(\alpha-\phi)(\gamma-\lambda)}}{2(\alpha-\phi)}$ & $Q_{i}=\lambda+\phi\left(\frac{P_{a}}{P_{i}}\right)^{1+\varepsilon}$ \\
\hline II & $\frac{P_{a}}{P_{i}}=\frac{-(\gamma+\beta) \pm \sqrt{(\gamma+\beta)^{2}+4(\alpha-\phi)} \lambda}{2(\alpha-\phi)}$ & $Q_{i}=\lambda+\phi\left(\frac{P_{a}}{P_{i}}\right)^{1+\varepsilon}$ \\
\hline III & $\frac{P_{a}}{P_{i}}=\frac{\gamma-\lambda}{\phi-\alpha-\beta}$ & $Q_{i}=\lambda+\phi\left(\frac{P_{a}}{P_{i}}\right)$ \\
\hline IV & $\frac{P_{a}}{P_{i}}=\frac{\lambda}{\alpha+\beta+\gamma-\phi}$ & $Q_{i}=\lambda+\phi\left(\frac{P_{a}}{P_{i}}\right)$ \\
\hline
\end{tabular}

Visto que o nível de preço industrial $\left(P_{i}\right)$ é determinado exogenamente, conforme indicado na equação (18), as expressões acima determinam, de fato, as variáveis endógenas $P_{a}$ e $Q_{i}$, como solução de equilíbrio, a partir da qual as demais variáveis endógenas do modelo podem ser determinadas recursivamente, bem como quaisquer outras combinações entre elas.

O modelo está, assim, pronto para ser operado em análises de causa e efeito entre variáveis exógenas ou parâmetros e variáveis endógenas. Todavia, em face da complexidade algébrica das soluções, a tradicional metodologia do cálculo diferencial torna-se extremamente complicada, já que as expressões das derivadas parciais envolvidas são de cálculo trabalhoso e difícil interpretação. Por esse motivo, optou-se, aqui, pelo método da simulação numérica, que consiste em arbitrar valores para as variáveis exógenas e parâmetros, de modo a obter uma situação inicial consistente e, a partir daí, realizar exercícios de estática-comparativa. Embora, a princípio, os resultados assim obtidos possam ser questionados acerca da generalidade das conclusões, eles têm a vantagem de dar respostas claras às perguntas que lhes são feitas, por meio dos exercícios. Por esse método, em vez de complicadas equações algébricas, os objetos 
de análise são grandezas numéricas facilmente comparáveis, com sinais positivos ou negativos que indicam, imediatamente, o sentido das relações envolvidas ${ }^{12}$.

A partir de cada vetor numérico das variáveis endógenas, podem-se construir, facilmente, quaisquer indicadores macroeconômicos que se desejar. Consideram-se, aqui, o produto real agregado $(y)$, como indicador do nível geral da atividade econômica; o deflator do PIB $(P)$, como indicador do nível geral dos preços; e as parcelas da renda de cada classe social relativas ao PIB, como indicador da distribuição funcional da renda. Essas parcelas foram denotadas por $A_{y}, W_{y}$ e $L_{y}$, para as classes dos agricultores, trabalhadores industriais e capitalistas, respectivamente. Utilizou-se o critério de Laspeyres para computar o deflator $(P)$, considerando-se, como fatores de ponderação (pesos), as contribuições de cada setor para a formação do PIB, apuradas na simulação inicial. A Tabela 1 apresenta os valores simulados das situações iniciais, para as variáveis exógenas e parâmetros, nas quatro combinações de elasticidades, e os correspondentes valores de equilíbrio das variáveis endógenas e indicadores macroeconômicos considerados ${ }^{13}$.

\footnotetext{
12 Se, como sugere Romer, modelos são mecanismos que os economistas usam para obter respostas objetivas a determinadas perguntas, os resultados, quando expressos em complicadas equações algébricas, são como respostas obscuras, de difícil compreensão, ao passo que, expressos em simples números reais, são como respostas claras e diretas.

13 Nem sempre os valores das soluções do sistema de equações são números inteiros. Portanto, cabe informar que alguns números da Tabela 1 são, na verdade, arredondamentos para duas casas decimais.
} 
REVISTA DE ECONOMIA E AGRONEGÓCIO, VOL.8, $N^{o} 1$

Tabela 1 - Simulação das situações iniciais

\begin{tabular}{|c|c|c|c|c|}
\hline Parâmetros & I & II & III & IV \\
\hline$a$ & 2,00 & 2,00 & 2,00 & 2,00 \\
\hline$c$ & 0,60 & 0,60 & 0,60 & 0,60 \\
\hline$\psi$ & 2,00 & 5,57 & 2,00 & 5,57 \\
\hline$\theta$ & 40,00 & 40,00 & 14,35 & 14,35 \\
\hline$\varepsilon$ & 1,00 & 1,00 & 0,00 & 0,00 \\
\hline$\eta$ & $-1,00$ & 0,00 & $-1,00$ & 0,00 \\
\hline$s$ & 0,45 & 0,45 & 0,45 & 0,45 \\
\hline$f$ & 0,20 & 0,20 & 0,20 & 0,20 \\
\hline$m$ & 1,00 & 1,00 & 1,00 & 1,00 \\
\hline$z$ & 2,00 & 2,00 & 2,00 & 2,00 \\
\hline$b$ & 1,00 & 1,00 & 1,00 & 1,00 \\
\hline$j$ & 0,20 & 0,20 & 0,20 & 0,20 \\
\hline$\lambda$ & 0,24 & 0,24 & 0,24 & 0,24 \\
\hline$\mu$ & 0,24 & 0,24 & 0,24 & 0,24 \\
\hline Variáveis exógenas & I & II & III & IV \\
\hline$I$ & 2,50 & 2,50 & 2,50 & 2,50 \\
\hline$w$ & 1,00 & 1,00 & 1,00 & 1,00 \\
\hline$P_{i}$ & 2,40 & 2,40 & 2,40 & 2,40 \\
\hline Variáveis endógenas & I & II & III & IV \\
\hline$Q_{i}$ & 9,72 & 9,72 & 9,72 & 9,72 \\
\hline$P_{a}$ & 0,86 & 0,86 & 0,86 & 0,86 \\
\hline$Q_{a}$ & 14,35 & 14,35 & 14,35 & 14,35 \\
\hline$W$ & 9,72 & 9,72 & 9,72 & 9,72 \\
\hline$L$ & 11,67 & 11,67 & 11,67 & 11,67 \\
\hline$N$ & 9,72 & 9,72 & 9,72 & 9,72 \\
\hline $\boldsymbol{Y}=P_{a} Q_{a}+P_{i} Q_{i}$ & 35,69 & 35,69 & 35,69 & 35,69 \\
\hline$P$ & 1,00 & 1,00 & 1,00 & 1,00 \\
\hline$y=Y / P$ & 35,69 & 35,69 & 35,69 & 35,69 \\
\hline$A_{y}=P_{a} Q_{a} / Y$ & 0,35 & 0,35 & 0,35 & 0,35 \\
\hline$W_{y}=W / Y$ & 0,27 & 0,27 & 0,27 & 0,27 \\
\hline$L_{y}=L / Y$ & 0,33 & 0,33 & 0,33 & 0,33 \\
\hline$x$ & 5,57 & 5,57 & 5,57 & 5,57 \\
\hline$X$ & 4,80 & 4,80 & 4,80 & 4,80 \\
\hline$M$ & 4,80 & 4,80 & 4,80 & 4,80 \\
\hline
\end{tabular}


A partir de cada um dos quadros iniciais acima, os exercícios consistem em recalcular os valores de equilíbrio das variáveis endógenas e dos indicadores macroeconômicos, após a simulação de determinada variação em qualquer uma das variáveis exógenas ou parâmetros, tudo o mais constante, e então analisar, comparativamente, a diferença percentual apurada entre a situação final e a situação inicial.

Neste estudo, são discutidos os resultados de três exercícios que envolvem deslocamentos da demanda industrial, da oferta agropecuária e da demanda agropecuária externa, expressos por variações de $10 \%$ na variável $I$ e nos parâmetros $\theta$ e $\psi$, respectivamente. Com o primeiro, visa-se captar o efeito do avanço da industrialização, uma vez que o deslocamento positivo da demanda de investimento leva, necessariamente, a uma expansão do setor industrial, seja esta realizada pelos capitalistas industriais, seja pelos agricultores. O segundo exercício visa captar o efeito do aumento da produtividade agropecuária ou da expansão da fronteira agrária. Dado que os investimentos feitos no setor agropecuário devem contribuir para a expansão da respectiva oferta, a análise conjunta dos dois primeiros exercícios serve para indicar a repercussão conjunta do aumento na demanda de investimento sobre a demanda e a oferta desse setor. Com o último exercício, procura-se captar os efeitos macroeconômicos da expansão da demanda agropecuária externa.

A Tabela 2 apresenta os resultados do primeiro exercício. Os números indicam que, como era de esperar de qualquer modelo macroeconômico, variações expansivas da demanda industrial estão associadas a variações, de sinal positivo, sobre o produto industrial $\left(Q_{i}\right)$ e sobre o preço agropecuário $\left(P_{a}\right)$. Verifica-se que a natureza dos resultados não depende das combinações de elasticidades, porquanto as diferenças entre eles, nos quatro casos considerados, são apenas de grau. Em valores absolutos, os impactos nos indicadores de produto e preços tendem a ser tão maiores quanto mais baixas forem as elasticidades-preço da oferta e da demanda agropecuária. Os indicadores distributivos indicam que o setor agropecuário tende a perder participação na distribuição da renda nacional, à medida que o processo de industrialização avança, a menos que as 
funções de oferta e demanda agropecuária sejam perfeitamente inelásticas, conforme indicado na coluna IV. O comportamento do índice de preços indica que a expansão do investimento está associada a um efeito inflacionário máximo, no caso IV, e mínimo, no caso I, o que ilustra, claramente, a tese estruturalista sobre a inflação nas economias de base agrarioexportadoras, em vias de industrialização. Os números das contas externas indicam que, em geral, o impacto tende a ser deficitário sobre o balanço de pagamentos, uma vez que a expansão industrial tende a ser acompanhada de aumento na importação de matérias-primas, e a expansão dos lucros induz ao aumento da importação de bens de consumo superior. Nos casos II e IV, em que a demanda agropecuária externa apresenta elasticidade unitária, o valor das exportações permanece constante porque o efeito do aumento no preço é compensado, exatamente, pela redução no quantum demandado. Assim, nesses casos, o déficit externo resulta apenas do aumento da importação. Quanto menos preço-elásticas a oferta e a demanda agropecuárias, menor o impacto negativo no balanço de pagamentos, sendo que, no caso extremo em que ambas as demandas são absolutamente inelásticas (caso IV), o saldo é zero, o que indica que o crescimento do valor exportado, devido ao efeito preço, é suficiente para compensar exatamente o aumento das importações.

Tabela 2 - Efeitos de uma expansão da demanda industrial

\begin{tabular}{ccccr}
\hline $\begin{array}{c}\text { Casos } \\
\text { Variáveis }\end{array}$ & I & II & III & IV \\
\hline$Q_{i}$ & 5,52 & 6,27 & 5,74 & 10,00 \\
$P_{a}$ & 1,39 & 1,98 & 3,15 & 10,00 \\
$Q_{a}$ & 1,39 & 1,98 & 0,00 & 0,00 \\
$P$ & 0,48 & 0,69 & 1,09 & 3,46 \\
$y$ & 4,08 & 4,77 & 3,71 & 6,32 \\
$A_{y}$ & $-1,70$ & $-1,40$ & $-1,61$ & 0,00 \\
$W_{y}$ & 0,90 & 0,74 & 0,85 & 0,00 \\
$L_{y}$ & 0,90 & 0,74 & 0,85 & 0,00 \\
$X$ & 0,00 & 1,98 & 0,00 & 10,00 \\
$M$ & 5,52 & 6,27 & 5,74 & 10,00 \\
\hline
\end{tabular}


A Tabela 3 apresenta os resultados que envolvem o deslocamento da oferta agropecuária. À primeira vista, os resultados negativos para os indicadores da atividade econômica podem parecer estranhos, mas não há nada de contraditório. Eles podem ser explicados como decorrência indireta da queda na renda dos agricultores, a qual, por sua vez, se deve ao fato de o aumento da quantidade ofertada implicar, em todos os casos, um efeito preço negativo, máximo no caso IV e mínimo no caso I. A diminuição resultante de poder aquisitivo dos agricultores leva à redução da demanda de produtos industriais, gerando, em consequência, redução no emprego e na renda dos trabalhadores assalariados. Para estes, haverá aumento do poder aquisitivo de alimentos, mas a redução no nível de emprego e da renda, dada sua propensão a consumir, levará à redução nos seus gastos com produtos industriais. Dado que a queda da demanda de bens industriais dos agricultores e trabalhadores implica queda nos lucros, a demanda dos capitalistas também será afetada negativamente. Uma coisa vai puxando a outra, no sentido de conduzir o produto industrial para um nível de equilíbrio mais baixo. Isso explica porque mudanças positivas no desempenho produtivo do setor agropecuário acabam tendo repercussões negativas no setor industrial. No balanço geral macroeconômico, o efeito positivo da elevação da produtividade agropecuária não compensa o efeito negativo da recessão industrial.

Tabela 3 - Efeitos de uma expansão da oferta agropecuária

\begin{tabular}{crrrr}
\hline $\begin{array}{c}\text { Casos } \\
\text { Variáveis }\end{array}$ & I & II & III & IV \\
\hline$Q_{i}$ & $-0,63$ & $-3,39$ & $-1,36$ & $-13,19$ \\
$P_{a}$ & $-5,14$ & $-7,29$ & $-11,08$ & $-28,36$ \\
$Q_{a}$ & 4,35 & 1,98 & 10,00 & 10,00 \\
$P$ & $-1,78$ & $-2,52$ & $-3,84$ & $-9,82$ \\
$y$ & 1,03 & $-1,62$ & 2,28 & $-6,82$ \\
$A_{y}$ & $-0,25$ & $-1,40$ & $-0,55$ & $-6,23$ \\
$W_{y}$ & 0,13 & 0,74 & 0,29 & 3,30 \\
$L_{y}$ & 0,13 & 0,74 & 0,29 & 3,30 \\
$X$ & 0,00 & $-7,29$ & 0,00 & $-28,36$ \\
$M$ & $-0,63$ & $-3,39$ & $-1,36$ & $-13,19$ \\
\hline
\end{tabular}


A queda nos preços agropecuários, em face da rigidez dos preços industriais, determina redução no nível geral de preços. Isso mostra que deslocamentos positivos da oferta agropecuária são eventos de bom augúrio para os mentores das políticas de estabilização. Com efeito, ao observar os exercícios I e II, em conjunto, pode-se concluir que os efeitos inflacionários da expansão dos investimentos no processo de industrialização poderiam ser anulados por medidas capazes de aumentar a produtividade agrícola ${ }^{14}$.

O efeito distributivo desfavorável aos agricultores, indicado pela análise das parcelas relativas, mostra que estes são os menos beneficiados ou os mais prejudicados pela expansão da oferta agropecuária. Quanto à classe trabalhadora industrial, se, por um lado, é afetada negativamente pela recessão industrial, por outro, acaba sendo compensada pela queda dos preços dos alimentos. Dado que o efeito sobre o nível de emprego é negativo, segue-se que os membros da classe trabalhadora mais favorecidos serão os que não perderem o emprego em consequência da recessão industrial. Por fim, verifica-se que o resultado sobre o balanço de pagamentos depende, fundamentalmente, da elasticidade da demanda agropecuária externa. Devido à recessão industrial, o valor das importações diminui nos quatro casos. Quanto às exportações, nos casos de elasticidade unitária (I e III), a queda no preço é compensada pelo aumento na quantidade exportada, de modo que o valor exportado permanece constante, determinando um resultado líquido positivo. Nos outros dois casos de elasticidade zero, o valor das exportações cai mais do que o das importações, determinando resultado líquido negativo. Em qualquer caso, isso é suficiente para mostrar que os grandes beneficiados são os países importadores de alimentos e matérias-primas básicas.

14 Este é o fundamento das propostas dos estruturalistas para a América Latina, visando conciliar crescimento
econômico, via industrialização, e estabilização de preços, por meio de reformas estruturais que visam aumentar
a produtividade no campo e políticas de rendas em vez de políticas ortodoxas restritivas de moeda e crédito. 
A partir daí, conclui-se que, sob as premissas do modelo, deslocamentos expansivos da oferta agropecuária interna, por si só, tenderiam a reduzir a participação do setor primário no PIB total. Fundamentalmente, isso se deve ao fato de os produtores rurais não poderem internalizar os benefícios de seus próprios esforços, os quais acabam sendo transferidos, na forma de preços mais baixos, para os consumidores urbanos e para os países estrangeiros importadores de commodities.

A Tabela 4 apresenta os resultados do exercício envolvendo expansão da demanda agropecuária. Os números indicam repercussões favoráveis ao nível de atividade do setor industrial, em todos os casos, sendo máximos quando ambas as elasticidades são zero e mínimos quando são unitárias, simultaneamente. Isso se deve ao fato de a expansão da demanda externa, ao aumentar o nível de preços agropecuários, elevar a renda dos agricultores, o que, por sua vez, induz ao aumento da demanda de bens industriais. A elevação da renda dos agricultores será tão mais acentuada quanto mais baixas forem as elasticidades-preço da demanda e oferta agropecuária, daí porque os efeitos são mais expansivos, porém mais inflacionários, no caso IV. A análise das parcelas distributivas indica que a classe rural será a mais beneficiada pelo crescimento econômico resultante. As duas últimas linhas da Tabela 4 indicam resultados favoráveis para as contas externas.

Em relação aos seus efeitos positivos sobre renda, sobre nível de emprego e sobre condição financeira do país, o exercício indica que qualquer expansão da demanda agropecuária externa será sempre bem-vinda. $\mathrm{O}$ problema são as implicações inflacionárias, conforme indicado pelo comportamento do nível geral de preços $(P)$. Com efeito, ao analisar, conjuntamente, os resultados do primeiro e do terceiro exercício, verificase que os efeitos da expansão da demanda agropecuária externa sobre o produto industrial e sobre o nível geral de preços operam no mesmo sentido que os da expansão da demanda industrial, em quaisquer dos quatro casos considerados. Constata-se assim que, em face da expansão 
da demanda, em qualquer que seja o setor, a expansão da oferta agropecuária é providencial para os objetivos de estabilização ${ }^{15}$.

Tabela 4 - Efeitos de uma expansão da demanda agropecuária externa

\begin{tabular}{ccccc}
\hline $\begin{array}{c}\text { Casos } \\
\text { Variáveis }\end{array}$ & I & II & III & IV \\
\hline$Q_{i}$ & 3,79 & 5,64 & 4,26 & 17,33 \\
$P_{a}$ & 3,00 & 4,43 & 6,85 & 27,85 \\
$Q_{a}$ & 3,00 & 4,43 & 0,00 & 0,00 \\
$P$ & 1,04 & 1,53 & 2,37 & 9,64 \\
$y$ & 3,51 & 5,21 & 2,72 & 10,33 \\
$A_{y}$ & 1,44 & 2,09 & 1,61 & 5,68 \\
$W_{y}$ & $-0,76$ & $-1,11$ & $-0,85$ & $-3,01$ \\
$L_{y}$ & $-0,76$ & $-1,11$ & $-0,85$ & $-3,01$ \\
$X$ & 10,00 & 14,87 & 10,00 & 40,63 \\
$M$ & 3,79 & 5,64 & 4,26 & 17,33 \\
\hline
\end{tabular}

A princípio, os dois últimos exercícios parecem ir de encontro a certos argumentos dos ufanistas do agronegócio, na medida em que parece sugerir que o crescimento econômico geral de países de "vocação" agrícola poderia ser alavancado pelo setor primário. Haveria algo de interessante nesse argumento, desde que se pudesse contar com uma expansão firme e continuada da demanda externa, caso em que políticas de estímulo à expansão da oferta teriam uma função coadjuvante muito importante. Todavia, as evidências indicam que os parâmetros dessa demanda são instáveis, sujeitos a movimentos aleatórios e flutuações cíclicas. A história brasileira é pródiga em exemplos de alternância entre anos de bons e maus mercados, para as exportações agrícolas, e de auge e declínio de certas atividades primárias, que, cada uma em sua época, chegaram a desfrutar de irresistíveis vantagens comparativas internacionais.

\footnotetext{
${ }_{15}$ Pode ser mostrado, mediante outro simples exercício, que, segundo os valores simulados nas condições iniciais, para manter constante o nível geral de preços, uma expansão da demanda externa, representada por um aumento de $10 \%$ na magnitude do parâmetro $\psi$, teria de ser acompanhada por uma expansão da oferta agropecuária representada por um aumento de apenas 5,5\% do parâmetro $\theta$. Nesse caso, o crescimento apurado para as variáveis $Q_{i}, y, X$ e $M$ seriam da ordem de $3,43 \%, 4,14 \%, 10 \%$ e $3,42 \%$, respectivamente.
} 
Por fim, uma análise conjunta dos três exercícios revela que, quanto maiores forem as elasticidade-preço das funções de oferta e demanda agropecuárias, menor tenderá a ser a variabilidade média absoluta das variáveis constantes nas Tabelas 2, 3 e 4, que serão mínimas, no caso I, em que ambas as elasticidades são unitárias, e máximas, no caso IV, em que ambas são iguais a zero. Isso mostra que, quanto maior for a resposta das forças de oferta e demanda aos sinais de preços, menor será o potencial de instabilidade e mais rápida a tendência de convergência para uma nova situação de equilíbrio. Não obstante, os exercícios indicam que as grandes questões sobre o desenvolvimento econômico das economias latino-americanas, levantadas pelos estruturalistas, não dependem da magnitude dessas elasticidades, contrariamente o que leva a pensar alguns trabalhos como o de Pastore (1973), por exemplo.

\section{Conclusão}

Uma análise conjunta dos três exercícios com o modelo estruturalista, aqui especificado, permite concluir que a renda real do setor agropecuário depende muito mais de condições externas a ele do que das condições internas. Ao induzir uma mudança de preço relativo favorável à agricultura, qualquer expansão da demanda industrial interna ou da demanda agropecuária externa contribuiria para o os ganhos dos agricultores mais do que qualquer coisa que eles pudessem fazer para melhorar seu desempenho produtivo, e vice-versa.

Choques na demanda agropecuária, de sinal positivo, teriam impactos favoráveis no produto real, no nível de emprego industrial e no saldo do balanço de pagamentos em transações correntes, e adversos no nível geral de preços internos, e vice-versa, sendo que, como era de esperar, os agricultores tenderiam a ser os mais beneficiados na distribuição da renda resultante de choques favoráveis, e vice-versa. Conclui-se, a partir daí, que, se um país bem aquinhoado pela natureza, como o Brasil, pudesse contar sempre com expansão sustentada da demanda mundial de produtos primários, a exploração de sua propalada "vocação agrícola", mediante 
adequadas políticas de incentivo à expansão continuada da oferta, poderia até ser pensada como estratégia interessante de inserção nacional na economia globalizada. Entretanto, conforme alertavam os estruturalistas latino-americanos, desde os primórdios do século passado, a história econômica tem mostrado que não é esse o caso. Ao contrário, os parâmetros da demanda externa de produtos primários são instáveis, sujeitos a flutuações aleatórias e movimentos cíclicos. Assim, as políticas de estímulo à expansão da oferta, por si só, acabam, no longo prazo, por favorecer mais os grandes centros metropolitanos, nacionais e estrangeiros, em detrimento dos trabalhadores rurais e do desenvolvimento econômico nacional.

Do ponto de vista nacional estratégico, políticas de incentivo à expansão da oferta agropecuária deveriam ser conjugadas com políticas industriais, no bojo de plano nacional autônomo, com vistas em fazer com que o avanço da industrialização e o crescimento econômico, com diversificação produtiva, sejam processados sem tensões inflacionárias e com distribuição funcional da renda mais equitativa.

Se bem analisada, a história mais recente tem mostrado que os sucessos alcançados nas exportações agropecuárias devem-se mais a fatores de ordem externa, sobre os quais não se dispõe de controle ou garantias de continuidade, como é o caso, por exemplo, da expansão chinesa e seus efeitos multiplicadores na economia mundial. O modelo, aqui utilizado, mostra que a estratégia chinesa de crescimento, via inserção internacional agressiva, tende a ser favorecida pelas políticas brasileiras de incentivo à expansão da oferta de commodities, como soja e minério de ferro. 


\section{Referências}

BLANCHARD, O. The State of Macro. Cambridge: NBER Working Papers Series, ${ }^{\circ} .14259,2008$.

GUDIN, E. Princípios de economia monetária. Rio de Janeiro: AGIR, 1976.

HAAN, H. H. D. "Hungary on the road to a mixed economy: a kaleckian computable general equilibrium approach". Economic System research, 1985, 13(1): 13-47.

HICKS, J. R. Crisis in keynesian economics. London: Basic Blackwell, 1974.

KALDOR, N. "Equilibrium theory and growth theory". In BASKIN, M. (Ed.) Economics and human welfare: Essays in honour of Tibor Scitovsky. New York: Academic Press, 1979.

KALECKI. M. "Costs and prices". In: Selected essays on the dynamics of the capitalist economy. Cambridge: Cambridge University Press, 1971.

KALECKI, M. "Diferença entre os problemas econômicos cruciais das economias capitalistas desenvolvidas e subdesenvolvidas". In Miglioli, J. (org) Crescimento e Ciclo das Economias Capitalistas, São Paulo: Hucitec, 1977.

LABINI. P. S. Oligopólio e progresso técnico. São Paulo: Forense/ EDUSP, 1980.

PARKIN, V. Chronic inflation in an industrializing economy: the Brazilian experience. Cambridge: Cambridge University Press, 1991.

PASTORE, A. C. A resposta da produção agrícola aos preços no Brasil. São Paulo: APEC, 1973. 
ROMER, D. Advanced macroeconomics. New York: McGraw Hill, 2000 .

SAYAD, J. Inflação e agricultura. Pesquisa e Planejamento Econômico, 1979, 9(1): 1-32.

SILVA, J. M. "Alocação de recursos na agricultura e a dinâmica da inflação". XXXI Congresso Brasileiro de Economia e Sociologia Rural, Ilhéus-BA, (agosto): 512-520, 1993.

SILVA, J. M. Impactos macroeconômicos do desempenho agropecuário. Revista de Economia e Agronegócio. 2008, Vol 6, No. 3 Set./Dez. Viçosa, MG.

FREEMAN, C. e SOETE, L. A economia da inovação industrial. Campinas: Editora Unicamp, 2008.

TAYLOR, L. Socially relevant policy analysis. Cambridge: Cambridge MIT Press, 1990.

TAYLOR, L. Reconstructing macroeconomics: structuralist proposals and critiques of the mainstream. Cambridge/London: Harvard University Press, 2004.

Abstract: The global economic crisis rescued Keynesianism. The current trends of the Brazilian economy, in what has been called "reprimarization", make timely reinvest structuralism in a position of greater prominence in the national economic debate. This is the main objective of this article. For this, we discuss a version of the macroeconomic model of "two-sectors," whereby it sought to show its relevance as a guide to thinking for a number of relevant socioeconomic issues, especially for third world countries. We seek also to demonstrate its consistency with certain empirical evidence and how it can be used as a basis for objective criticism of certain economic strategies that have been proposed for Brazil.

Keywords: Structuralism, macroeconomics, two sector model, Brazil. 